
\title{
25 Research Square \\ Factors Associated With Diagnostic Delay of Pulmonary Tuberculosis in China
}

\section{Caihong Xu}

National Center for Tuberculosis Control and Prevention

Xiaomeng Zhang

Tianjin center for tuberculosis control

\section{Yan Liu}

Peking UnionMedical College $₫$ Beijing $₫$ China

\section{Yinyin Xia}

National Center for Tuberculosis Control and Prevention

\section{Li Wang}

Institute of Basic Medical Sciences Chinese Academy of Medical Sciences

\section{Lixia Wang}

National Center for Tuberculosis Control and Prevention

Hui Zhang ( $\boldsymbol{\sigma}$ zhanghui@chinacdc.cn )

National Center for Tuberculosis Control and Prevention, China Centre for Disease Control (CDC) https://orcid.org/0000-0002-3989-2304

\section{Research Article}

Keywords: Diagnosis, Delay, Pulmonary tuberculosis

Posted Date: April 13th, 2021

DOI: https://doi.org/10.21203/rs.3.rs-404351/v1

License: (c) (i) This work is licensed under a Creative Commons Attribution 4.0 International License. Read Full License 


\section{Abstract}

\section{Background}

Tuberculosis (TB) is still a great challenge to public health in China. Most of the transmission occurs between the onset of symptoms and initiation of treatment. Diagnosis delay is a major barrier to effective management of the disease. Determining the factors associated with patient and provider delay of TB diagnosis and treatment may contribute to TB prevention and control.

\section{Methods}

A cross-sectional survey of pulmonary tuberculosis registed in the National Tuberculosis programme was conducted in 22 counties of 6 provinces in China. All consecutively registered patients during January to June 2017 were interviewed using a structured questionnaire. The time from the onset of symptoms to the date of diagnosis was analyzed. Bivariate and logistics regression were applied to analyze the risk factors of delay.

\section{Results}

The median time from onset of symptoms to diagnosis was 23 days (interquartile range [IQR]: 5-53days). The risk of delayed diagnosis was higher in the central $(\mathrm{OR}=3.27,95 \% \mathrm{Cl} 1.39-7.68)$ and eastern regions $(\mathrm{OR}=1.48,95 \% \mathrm{Cl} 1.04-2.10)$ than in the western regions. Rural TB patients have a longer diagnosis delay than those in urban areas $(\mathrm{OR}=1.44,95 \% \mathrm{Cl} 1.00-2.08)$. The asymptomatic TB patients had a longer diagnosis delay than TB patients with clinical symptoms $(\mathrm{OR}=0.20,95 \% \mathrm{Cl} 0.13-0.31)$.

\section{Conclusions}

A high propotion of TB patients showed diagnostic delay in China especially in some low economic level areas. Multiple measures should be taken to shorten the delay, such as to increase public awareness of the disease and expansion the quality assured facility in economic less-developed regions.

\section{Trial registration}

Not applicable

\section{Introduction}

Tuberculosis (TB) remains to be a major public health threat, it is estimated that there were 10 million new cases of TB worldwide and more than 1.2 million deaths from TB ${ }^{1}$. The diagnosis delay present a major obstacle to the control of TB epidemic. This is a serious concern due to the fact that each of the patient may infect $10-15$ people each year, eventually creating a public health problem and even lead to economic hardship ${ }^{2}$. Ensuring universal access to quality-assured and early diagnosis of TB will diminish 
transmission, avert deaths and prevent suffering caused by TB, which can help countries to move towards elimination of the disease.

China is one of the TB high burden country which accounting for $8.4 \%$ of the global TB burden and $50 \%$ of the burden in Western Pacific region ${ }^{[1,2] 1-2}(1,2)$. The fifth national tuberculosis prevalence survey showed that, from 1990 to 2010 , the prevalence of pulmonary tuberculosis decreased from $611 / 100,000$ to $442 / 100,000$, the decline rate was only $28 \%{ }^{[3] 3}(3)$. The unsatisfied decline of pulmonary tuberculosis (PTB) might due to long diagnostic delay of tuberculosis. The Directly Observed Treatment, Short-course [DOTS] strategy has been adopted in China since 1990s. The key elements of DOTS strategy were early diagnosis and prompt treatment initiation. Considering the TB burden and human capacity, passive casefinding strategy has always been the main approach applied by National Tuberculosis Programme (NTP) in China, which contributes more than $95 \%$ TB patients notification ${ }^{4}$. Under the passive-case finding principle, symptomatic TB patients voluntarily visit any kind of health facilities to seek medical care, all the suspected TB patients and confirmed TB patients should be referred to TB designated medical facilities. People undetected for long time or late detection may worse the disease, increase mortality and result in sustained spread of tuberculosis in the community.

Identifying reasons for delay in diagnosis is important for the health system to find ways to treat patients as early as possible, and hence reduce the suffering of patients and transmission of the disease. Information on diagnostic delay is important for evaluation and improvement of the TB control programmes. Some small-scale studies of diagnostic delay have been conducted in China ${ }^{5-10}$, which reported diagnostic delay were very significantly from around 30 days in Shanghai ${ }^{5}$ to 60 days in Shanxi province $^{6}$. Factors attributing to the delay in diagnosis are also likely to vary in different settings, poverty, non-residents, lack of health knowledge and default of health insurance et al were reported related to long delay in diagnosis. But no nationally representative data are available.

We conducted a nation-wide study of diagnostic delay in 22 counties, with the aims to evaluate the extend of diagnostic delay in tuberculosis case finding and identify risk factors associated with long diagnostic delay within in NTP in China.

\section{Method}

\section{Study design}

This was a cross-sectional study involving primary data collection.

\section{Setting}

\section{General setting}

China is a developing country has total population of 1.4 billion and 2851 counties, the per capita gross national product was10 349 US\$ in $2019^{11}$. The health care delivery system is "mixed" with a dominant 
role for public sector institutions ${ }^{12}$.

\section{National TB Programme (NTP)}

The National center for tuberculosis control and prevention (NCTB), which belongs to China center for disease control (CDC), manages the NTP. TB basic management units (BMU) are established at county level. One authorized TB designated medical facility (TB designated hospital, TB dispensary or CDC) is responsible for TB diagnosis and treatment at each BMU level. TB patients are provided free chest radiography, sputum smear test and first-line drugs in TB designated medical facilities.

\section{Study population}

Eligible were all drug-susceptible tuberculosis patients who had been diagnosed during January and June 2017 within in NTP.

\section{Sampling strategy}

We adopted multi-stage stratified cluster sampling. The stratifying factors were region (east/middle/west) and residence (rural/urban). The steps followed in sampling have been summarized in Annex I.

\section{Sample size}

Assuming diagnose delay was $30 \%{ }^{13}$, relative precision as 0.2 and a error as 0.05 , average cluster (defined at county level) size of 50 , between-cluster variation of 0.4 , design effect of 4.36 and anticipating a non-response rate of $10 \%$, the final sample size was 960 , to be sampled from 22 clusters. (see AnnexII)

\section{Survey instrument}

A structured questionnaire was developed addressing health seeking behavior of TB patients based on clinical experience and review of relevant literature. The questionnaire collected information including: 1) demographic and socio-economic variables: sex, age, education level, area of residence, economic status, 2) clinical presentations: cough, fever, night sweats, hemoptysis, weight loss, anorexia, fatigue, and dyspnea 3) health care seeking experiences of the subjects from the onset of symptoms to obtaining a TB diagnosis.

It was pre-tested prior to the start of the study in one Changping district BMU in Beijing and modifications were made to arrive to the final version. Each interview lasted approximately 20 minutes. A written consent was secured from every eligible tuberculosis patient before inclusion into the survey. Informed consent and responses for children under 18 years of age were obtained from the closest accompanying relative.

Diagnostic delay was used to reflect the promptness of patient's access to TB care. Diagnostic delay was defined as the time interval from the onset of symptoms to the confirmed TB diagnosis longer than 14 
days.

\section{Data management and analysis}

Data were double entered and validated using EpiData (version 3.1 EpiData Association, Odense, Denmark) during July to December 2017. The analysis was conducted using STATA (version 12.1, copyright 1985-2011 StataCorp LP USA). Beyond the descriptive statistics, associations between the dependent variables (diagnosis delay) and the independent variables were analyzed by calculating the ORs test and respective 95\% confidence intervals $(\mathrm{Cl})$. Independent variables that showed marginal associations $(P<0.20)$ in the bivariate analysis were used in a logistic regression analysis in order to identify independent predictors of diagnosis delay $>14$ days. The association of predictor variables with the dependent variables was assessed by using $95 \% \mathrm{Cl}$ and adjusted odds ratio (AOR). A p-value of $<0.05$ was regarded as statistically significant.

\section{Results}

\section{Socio-demographic characteristics of patients}

Table 1 shows the characteristics of the participants A total of 974 tuberculosis patients were included in our study. Among them, 387(39.7\%) and 380(39.0\%) came from eastern and western regions respectively. $396(40.7 \%)$ patients were aged $45-64$ and $682(70.0 \%)$ patients were male. The majority of the participants were completed primary and middle school education, which accounting for $58.8 \%$. $467(48.0 \%)$ were irregular earning, and $566(58.1 \%)$ of the participants were their family prime income earner. 894 (91.8\%) were newly diagnosed TB patients and 615(63.1\%) participants were not hospitalized. $810(87.4 \%)$ participants had symptom, and the main symptom of the participants were cough (76.5\%), followed by expectoration (55.1\%). 589(60.5\%) participants had chronic disease and $659(67.7 \%)$ were registered at TB designated hospitals. There were 728 patients with the new rural cooperative medical scheme, accounting for $74.7 \%$. 
Table 1

Socio-demographic characteristics of pulmonary tuberculosis patients in diagnosis delay survey in China,2017 ( $\mathrm{n}=974)$

\begin{tabular}{|c|c|c|c|}
\hline \multicolumn{2}{|l|}{ Characteristics } & \multirow{2}{*}{$\begin{array}{l}\mathbf{N} \\
974\end{array}$} & \multirow{2}{*}{$\begin{array}{l}(\%) \\
(100)\end{array}$} \\
\hline Overall & & & \\
\hline \multirow[t]{3}{*}{ Region } & East & 387 & $(39.73)$ \\
\hline & Middle & 207 & $(21.25)$ \\
\hline & West & 380 & $(39.01)$ \\
\hline \multirow[t]{4}{*}{ Age group in years } & $<15$ & 3 & $(0.31)$ \\
\hline & $15-44$ & 330 & $(33.88)$ \\
\hline & $45-64$ & 396 & $(40.66)$ \\
\hline & $\geq 65$ & 245 & $(25.15)$ \\
\hline \multirow[t]{2}{*}{ Gender } & Male & 682 & $(70.02)$ \\
\hline & Female & 292 & $(29.98)$ \\
\hline \multirow[t]{5}{*}{ Education } & Illiterate or not completed primary school & 177 & $(18.17)$ \\
\hline & Completed primary school & 259 & $(26.59)$ \\
\hline & Completed middle school & 314 & $(32.24)$ \\
\hline & Completed high school & 154 & $(15.81)$ \\
\hline & Completed college and above & 70 & (7.19) \\
\hline \multirow[t]{3}{*}{ Economic activity } & Formal sector(regular salary) & 225 & $(23.1)$ \\
\hline & Informal sector(irregular earning) & 467 & $(47.95)$ \\
\hline & Economically inactive & 282 & $(28.95)$ \\
\hline \multirow[t]{2}{*}{ Prime income earner } & Yes & 566 & $(58.11)$ \\
\hline & No & 408 & $(41.89)$ \\
\hline \multirow[t]{2}{*}{ Migrant status } & Yes & 8 & $(0.82)$ \\
\hline & No & 966 & (99.18) \\
\hline \multirow[t]{4}{*}{ Marital status } & Married & 155 & $(15.91)$ \\
\hline & Unmarried & 606 & $(62.22)$ \\
\hline & Divorced & 30 & $(3.08)$ \\
\hline & Widowed & 73 & $(7.49)$ \\
\hline
\end{tabular}




\begin{tabular}{|c|c|c|c|}
\hline \multicolumn{2}{|l|}{ Characteristics } & \multirow{2}{*}{$\begin{array}{l}\mathbf{N} \\
110\end{array}$} & \multirow{2}{*}{$\begin{array}{l}(\%) \\
(11.29)\end{array}$} \\
\hline & Missing & & \\
\hline \multirow[t]{2}{*}{ Residence } & Urban & 333 & $(34.19)$ \\
\hline & Rural & 641 & $(65.81)$ \\
\hline \multirow[t]{2}{*}{ TB Category } & New & 894 & (91.79) \\
\hline & Previously treated & 80 & $(8.21)$ \\
\hline \multirow[t]{3}{*}{ Sputum status at diagnosis } & Unknown & 40 & $(4.11)$ \\
\hline & Positive & 279 & $(28.64)$ \\
\hline & Negative & 655 & $(67.25)$ \\
\hline \multirow[t]{2}{*}{ Hospitalization } & Yes & 359 & $(36.86)$ \\
\hline & No & 615 & $(63.14)$ \\
\hline \multirow[t]{2}{*}{ Symptom } & Yes & 810 & $(87.38)$ \\
\hline & No & 117 & $(12.62)$ \\
\hline \multirow[t]{3}{*}{ HIV } & Positive & 11 & $(1.13)$ \\
\hline & Negative & 332 & $(34.09)$ \\
\hline & Unknown & 631 & $(64.78)$ \\
\hline \multirow[t]{2}{*}{ Combordity } & Yes & 589 & $(60.47)$ \\
\hline & No & 385 & $(39.53)$ \\
\hline \multirow[t]{6}{*}{ Insurance } & Urban employee basic medical insurance((UEBMI) & 88 & (9.03) \\
\hline & Urban residence basic medical insurance(URBMI) & 92 & (9.45) \\
\hline & New rural coopertive medical scheme((NCMS) & 728 & $(74.74)$ \\
\hline & commercial insurance & 13 & $(1.33)$ \\
\hline & mixed insurance & 16 & $(1.64)$ \\
\hline & None & 37 & (3.8) \\
\hline \multirow[t]{3}{*}{ Place of registration } & TB designated hospital & 659 & $(67.66)$ \\
\hline & CDC hospital & 127 & $(13.04)$ \\
\hline & TB dispensary & 188 & $(19.3)$ \\
\hline
\end{tabular}




\section{Duration and Distribution of diagnostic time}

Figure 1 shows the distribution of time from symptoms onset to diagnosis of all the 974 pulmonary TB patients. The median diagnosis time for all cases was 23 days (IQR 5-53 days). The mean diagnosis time was $37.1 \pm 43.3$ days. 380 (39.0\%) were diagnosed within 2 weeks. The diagnosis time was longer than 120 days in 65 cases, accounting for $6.7 \%$.

\section{Factors associated with Diagnostic delay}

Table 2 shows the results of regression analysis. Patients with TB in eastern regions had a higher risk of diagnosis delay than those in western regions $(\mathrm{OR}=1.85,95 \% \mathrm{Cl} 1.38-2.48)$. Patients completed high school education had a lower risk of diagnosis delay than those with illiterate or not completed primary school ( $\mathrm{OR}=0.54,95 \% \mathrm{Cl} 0.35-0.84)$. Rural TB patients had a longer diagnosis delay than urban patients $(\mathrm{OR}=1.44,95 \% \mathrm{Cl} 1.10-1.88)$. Patients hospitalized with tuberculosis had a higher risk of diagnosis delay than non-hospitalized patients $(\mathrm{OR}=1.35,95 \% \mathrm{Cl} 1.03-1.77)$. Patients with clinical symptoms diagnosis delay had a lower risk than patients without clinical symptoms $(\mathrm{OR}=0.21,95 \% \mathrm{Cl} 0.14-0.32)$. Patients enrolled at TB dispensary had a higher risk of diagnosis delay than those enrolled at TB designated hospital $(\mathrm{OR}=2.16,95 \% \mathrm{Cl} 1.50-3.10)$. Social-demographic factors such as age, gender and marital status, and social-economic conditions such as economic status and form of medical insurance had no statistical significance on diagnosis delay. 
Table 2

Association of clinical and social-demographic factors with diagnosis delay among patients in China,2017 ( $\mathrm{n}=974)$

\begin{tabular}{|c|c|c|c|c|}
\hline \multirow[t]{2}{*}{ Characteristics } & & $\begin{array}{l}\text { Diagnosis } \\
\text { time(days) }\end{array}$ & OR & $95 \% \mathrm{Cl}$ \\
\hline & & \multicolumn{3}{|l|}{ Median(IQR*) } \\
\hline \multicolumn{2}{|l|}{ Overall } & \multicolumn{3}{|l|}{$23.0(5.0-53.0)$} \\
\hline \multirow[t]{3}{*}{ Region } & West & $17.0(3.0-50.5)$ & ref & \\
\hline & East & $29.0(10.0-56.0)$ & 1.85 & $\begin{array}{l}1.38- \\
2.48\end{array}$ \\
\hline & Middle & $21.0(3.0-53.0)$ & 1.41 & $\begin{array}{l}1.00- \\
2.00\end{array}$ \\
\hline \multirow[t]{3}{*}{ Age group in years } & $\leq 44$ & $21.0(4.0-49.0)$ & ref & \\
\hline & $45-64$ & $23.0(4.0-51.5)$ & 1.09 & $\begin{array}{l}0.81- \\
1.46\end{array}$ \\
\hline & $\geq 65$ & $24.0(9.0-59.0)$ & 1.25 & $\begin{array}{l}0.89- \\
1.75\end{array}$ \\
\hline \multirow[t]{2}{*}{ Gender } & Male & $22.5(5.0-52.0)$ & ref & \\
\hline & Female & $23.5(5.0-59.5)$ & 0.92 & $\begin{array}{l}0.7- \\
1.22\end{array}$ \\
\hline \multirow[t]{5}{*}{ Education } & $\begin{array}{l}\text { Illiterate or not completed primary } \\
\text { school }\end{array}$ & $28.0(6.0-67.0)$ & ref & \\
\hline & Completed primary school & $23.0(7.0-57.0)$ & 0.86 & $\begin{array}{l}0.58- \\
1.27\end{array}$ \\
\hline & Completed middle school & $25.5(7.0-52.0)$ & 1.07 & $\begin{array}{l}0.73- \\
1.57\end{array}$ \\
\hline & Completed high school & $13.0(1.0-34.0)$ & 0.54 & $\begin{array}{l}0.35- \\
0.84\end{array}$ \\
\hline & Completed college and above & $27.0(3.0-61.0)$ & 1.02 & $\begin{array}{l}0.57- \\
1.82\end{array}$ \\
\hline \multirow[t]{2}{*}{ Economic activity } & Formal sector(regular salary) & $20.0(4.0-40.0)$ & ref & \\
\hline & Informal sector(irregular earning) & $23.0(6.0-53.0)$ & 1.04 & $\begin{array}{l}0.76- \\
1.45\end{array}$ \\
\hline
\end{tabular}

*IQR: interquartile range;

\#UEBMI: Urban employee basic medical insurance; URBMI: Urban residence basic medical insurance; NCMS: New rural coopertive medical scheme 


\begin{tabular}{|c|c|c|c|c|}
\hline \multicolumn{2}{|l|}{ Characteristics } & \multirow{2}{*}{$\begin{array}{l}\text { Diagnosis } \\
\text { time(days) } \\
\text { Median(IQR*) }\end{array}$} & \multirow[t]{2}{*}{ OR } & \multirow[t]{2}{*}{$95 \% \mathrm{Cl}$} \\
\hline & & & & \\
\hline & Economically inactive & $25.5(5.0-61.0)$ & 1.15 & $\begin{array}{l}0.8- \\
1.64\end{array}$ \\
\hline \multirow[t]{2}{*}{ Prime income earner } & No & $21.0(5.0-54.0)$ & ref & \\
\hline & Yes & $23.0(5.0-52.0)$ & 1.05 & $\begin{array}{l}0.81- \\
1.36\end{array}$ \\
\hline \multirow[t]{2}{*}{ Migrant status } & No & $23.0(5.0-53.0)$ & ref & \\
\hline & Yes & $5.5(0.5-29.5)$ & 0.21 & $\begin{array}{l}0.04- \\
1.05\end{array}$ \\
\hline \multirow[t]{5}{*}{ Marital status } & Married & $26.0(6.0-51.0)$ & ref & \\
\hline & Unmarried & $24.0(7.0-57.0)$ & 0.97 & $\begin{array}{l}0.67- \\
1.40\end{array}$ \\
\hline & Divorced & $31.0(6.0-53.0)$ & 1.64 & $\begin{array}{l}0.69- \\
3.93\end{array}$ \\
\hline & Widowed & $21.0(3.0-68.0)$ & 0.96 & $\begin{array}{l}0.54- \\
1.70\end{array}$ \\
\hline & Missing & $14.5(1.0-37.0)$ & 0.60 & $\begin{array}{l}0.36- \\
0.98\end{array}$ \\
\hline \multirow[t]{2}{*}{ Residence } & Urban & $17.0(3.0-51.0)$ & ref & \\
\hline & Rural & $27.0(6.0-57.0)$ & 1.44 & $\begin{array}{l}1.1- \\
1.88\end{array}$ \\
\hline \multirow[t]{2}{*}{ TB Category } & New & $24.0(6.0-54.0)$ & ref & \\
\hline & Previously treated & $16.0(1.0-34.5)$ & 0.81 & $\begin{array}{l}0.51- \\
1.28\end{array}$ \\
\hline \multirow{3}{*}{$\begin{array}{l}\text { Sputum status at } \\
\text { diagnosis }\end{array}$} & Unknown & $20.5(6.5-56.5)$ & ref & \\
\hline & Positive & $30.0(6.0-61.0)$ & 1.25 & $\begin{array}{l}0.63- \\
2.47\end{array}$ \\
\hline & Negative & $20.0(4.0-48.0)$ & 0.97 & $\begin{array}{l}0.51- \\
1.86\end{array}$ \\
\hline Hospitalization & No & $21.0(4.0-52.0)$ & ref & \\
\hline
\end{tabular}

*IQR: interquartile range;

\#UEBMI: Urban employee basic medical insurance; URBMI: Urban residence basic medical insurance; NCMS: New rural coopertive medical scheme 


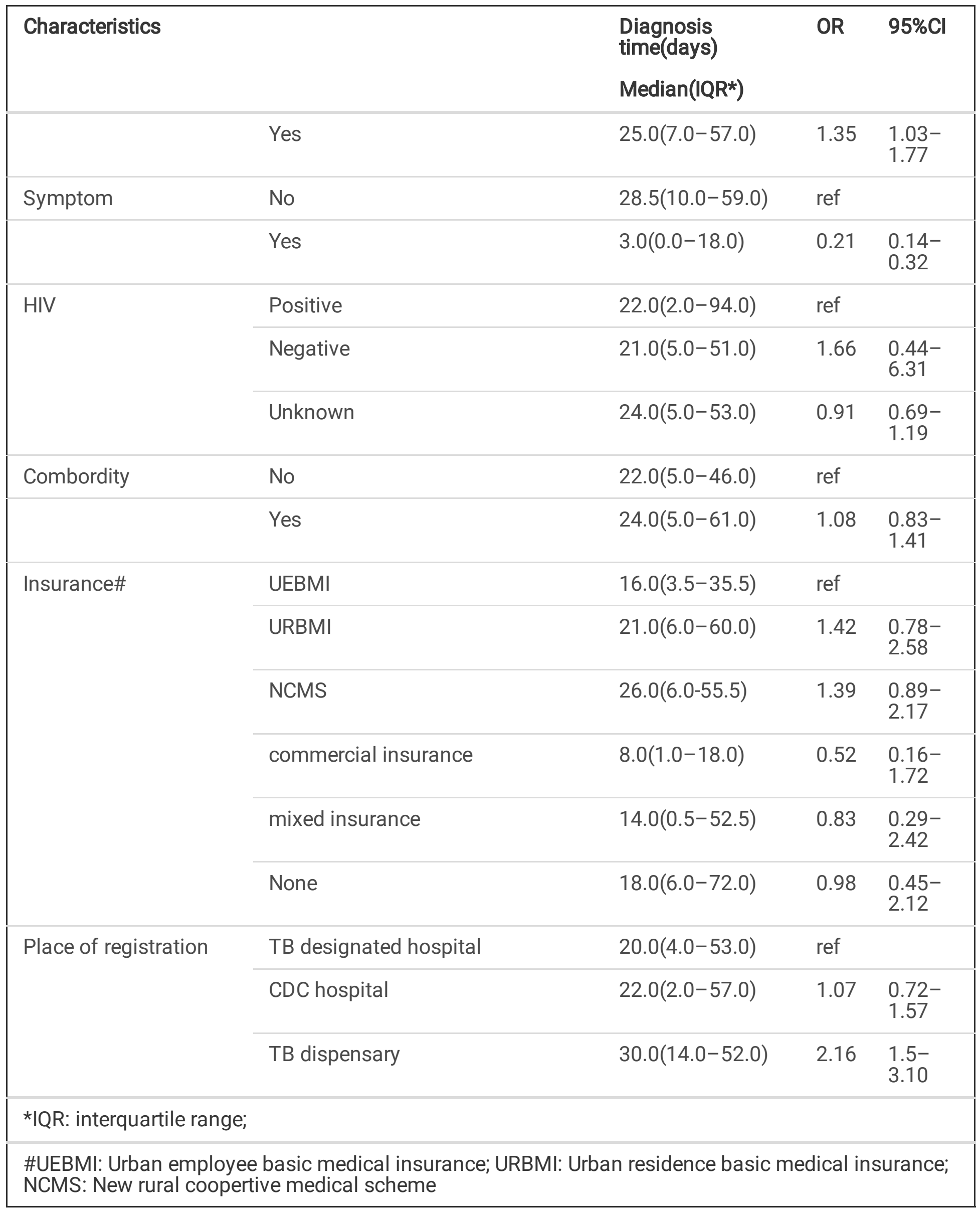




\section{Multivariate logistic regression for delayed diagnosis}

Table 3 shows the multivariate logistic regression analysis results. The results showed that the risk of delayed diagnosis was higher in the central $(\mathrm{OR}=3.27,95 \% \mathrm{Cl} 1.39-7.68)$ and eastern regions $(\mathrm{OR}=1.48$, $95 \% \mathrm{Cl} 1.04-2.10)$ than in the western regions. Rural TB patients have a longer diagnosis delay than those in urban areas $(\mathrm{OR}=1.44,95 \% \mathrm{Cl} 1.00-2.08)$. The asymptomatic TB patients had a longer diagnosis delay than TB patients with clinical symptoms $(\mathrm{OR}=0.20,95 \% \mathrm{Cl} 0.13-0.31)$. 
Table 3

Multivariable linear regression for factors associated with diagnosis delay among patients in China,2017 $(n=974)$

\begin{tabular}{|c|c|c|c|c|}
\hline \multicolumn{2}{|l|}{ Characteristics } & $\begin{array}{l}\text { Diagnosis } \\
\text { time(days) } \\
\text { Median(IQR*) }\end{array}$ & OR & $95 \% \mathrm{Cl}$ \\
\hline \multirow[t]{3}{*}{ Region } & West & $17.0(3.0-50.5)$ & ref & \\
\hline & Middle & $29.0(10.0-56.0)$ & 3.27 & $\begin{array}{l}1.39- \\
7.68\end{array}$ \\
\hline & East & $21.0(3.0-53.0)$ & 1.48 & $\begin{array}{l}1.04- \\
2.10\end{array}$ \\
\hline \multirow[t]{5}{*}{ Education } & $\begin{array}{l}\text { Illiterate or not completed primary } \\
\text { school }\end{array}$ & $28.0(6.0-67.0)$ & ref & \\
\hline & Completed primary school & $23.0(7.0-57.0)$ & 0.89 & $\begin{array}{l}0.58- \\
1.37\end{array}$ \\
\hline & Completed middle school & $25.5(7.0-52.0)$ & 1.15 & $\begin{array}{l}0.74- \\
1.78\end{array}$ \\
\hline & Completed high school & $13.0(1.0-34.0)$ & 0.70 & $\begin{array}{l}0.42- \\
1.17\end{array}$ \\
\hline & Completed college and above & $27.0(3.0-61.0)$ & 1.14 & $\begin{array}{l}0.55- \\
2.37\end{array}$ \\
\hline \multirow[t]{5}{*}{ Marital status } & Married & $26.0(6.0-51.0)$ & ref & \\
\hline & Unmarried & $24.0(7.0-57.0)$ & 0.77 & $\begin{array}{l}0.50- \\
1.20\end{array}$ \\
\hline & Divorced & $31.0(6.0-53.0)$ & 1.23 & $\begin{array}{l}0.47- \\
3.23\end{array}$ \\
\hline & Widowed & $21.0(3.0-68.0)$ & 0.74 & $\begin{array}{l}0.38- \\
1.43\end{array}$ \\
\hline & Missing & $14.5(1.0-37.0)$ & 1.12 & $\begin{array}{l}0.46- \\
2.71\end{array}$ \\
\hline \multirow[t]{2}{*}{ Migrant status } & No & $23.0(5.0-53.0)$ & ref & \\
\hline & Yes & $5.5(0.5-29.5)$ & 0.19 & $\begin{array}{l}0.03- \\
1.06\end{array}$ \\
\hline
\end{tabular}

The variables in the univariate logistic analysis whose significance level was less than 0.2 were introduced into the model for the multivariate logistic regression analysis.

*IQR: interquartile range;

\#UEBMI: Urban employee basic medical insurance; URBMI: Urban residence basic medical insurance; NCMS: New rural coopertive medical scheme 


\begin{tabular}{|c|c|c|c|c|}
\hline \multirow[t]{2}{*}{ Characteristics } & & Diagnosis & OR & $95 \% \mathrm{Cl}$ \\
\hline & & \multicolumn{3}{|l|}{ Median(IQR*) } \\
\hline \multirow[t]{2}{*}{ Residence } & Urban & $17.0(3.0-51.0)$ & ref & \\
\hline & Rural & $27.0(6.0-57.0)$ & 1.44 & $\begin{array}{l}1.00- \\
2.08\end{array}$ \\
\hline \multirow[t]{2}{*}{ Hospitalization } & No & $21.0(4.0-52.0)$ & ref & \\
\hline & Yes & $25.0(7.0-57.0)$ & 0.99 & $\begin{array}{l}0.72- \\
1.36\end{array}$ \\
\hline \multirow[t]{2}{*}{ Symptom } & No & $28.5(10.0-59.0)$ & ref & \\
\hline & Yes & $3.0(0.0-18.0)$ & 0.20 & $\begin{array}{l}0.13- \\
0.31\end{array}$ \\
\hline \multirow[t]{6}{*}{ Insurance\# } & UEBMI & $16.0(3.5-35.5)$ & ref & \\
\hline & URBMI & $21.0(6.0-60.0)$ & 1.67 & $\begin{array}{l}0.82- \\
3.40\end{array}$ \\
\hline & NCMS & $26.0(6.0-55.5)$ & 1.36 & $\begin{array}{l}0.75- \\
2.45\end{array}$ \\
\hline & commercial insurance & $8.0(1.0-18.0)$ & 0.54 & $\begin{array}{l}0.13- \\
2.27\end{array}$ \\
\hline & mixed insurance & $14.0(0.5-52.5)$ & 1.06 & $\begin{array}{l}0.31- \\
3.66\end{array}$ \\
\hline & None & $18.0(6.0-72.0)$ & 0.95 & $\begin{array}{l}0.38- \\
2.25\end{array}$ \\
\hline \multirow{3}{*}{$\begin{array}{l}\text { Place of } \\
\text { registration }\end{array}$} & TB designated hospital & $20.0(4.0-53.0)$ & ref & \\
\hline & CDC hospital & $22.0(2.0-57.0)$ & 0.55 & $\begin{array}{l}0.21- \\
1.45\end{array}$ \\
\hline & TB dispensary & $30.0(14.0-52.0)$ & 1.15 & $\begin{array}{l}0.72- \\
1.86\end{array}$ \\
\hline \multicolumn{5}{|c|}{$\begin{array}{l}\text { The variables in the univariate logistic analysis whose significance level was less than } 0.2 \text { were } \\
\text { introduced into the model for the multivariate logistic regression analysis. }\end{array}$} \\
\hline \multicolumn{5}{|c|}{ *IQR: interquartile range; } \\
\hline \multicolumn{5}{|c|}{$\begin{array}{l}\text { \#UEBMI: Urban employee basic medical insurance; URBMI: Urban residence basic medical insurance, } \\
\text { NCMS: New rural coopertive medical scheme }\end{array}$} \\
\hline
\end{tabular}

\section{Discussion}


This study was the first nationally representative survey to show the diagnostic timeliness. Our study indicates that more than $60 \%$ cases experience TB diagnosis delay in China. The median time between the onset of symptoms and confirmed diagnosis was 23 days which was similar as other developing counties such as Nepal ${ }^{14}$, India ${ }^{15}$, Bangladesh ${ }^{16}$ and Tanzania ${ }^{17}$, that studies showed that the estimated average delays was 9.5-60 days, also was consistant with the results in Shenzhen in China ${ }^{8}$. All the results suggested us that the diagnostic delay was common in TB care, more effects and measures should be put in placed to improve such situation.

We found that there were significant regional differences in diagnosis delay time. The risk of delayed diagnosis of tuberculosis patients in eastern and central regions was higher than that in western regions, which was basically consistent with the results of domestic studies on sub-regions such as northwest ${ }^{6}$ and Shandong ${ }^{18}$. The reason may be that there are more comprehensive hospitals in the eastern and central regions, and patients choose comprehensive hospitals as the first treatment unit due to their doctor visiting habits. However, in recent years, a number of investigations and studies have found that the ability of comprehensive hospitals to identify tuberculosis is not as sensitive as expected ${ }^{19-20}$, which leads to the prolongation of patient diagnosis time.

The fifth national TB epidemiology survey showed that the public awareness of TB is rural areas and urban areas were $51.7 \%$ and $63.4 \%$ respectively ${ }^{21}$, the lower awareness level of TB in urban areas might lead to the high risk of diagnostic delay as we found in the results. On the other hand, the patients residing in rural areas have greater chance of diagnostic delay is almost certainly due to the barriers of access to diagnosis such as lack of diagnostic facilities, lack of quality services and availability of trained staffs.

The risk of diagnostic delay in asymptomatic TB patients is five times higher than that in symptomatic TB patients, which may be due to the fact that most asymptomatic TB patients do not seek medical care because they are unaware of their disease. This is very consistent with the domestic and foreign research results $^{9,22}$. That was mainly due to the current passive case finding strategy we adopt in China.

Among the results of our univariate analysis, one of the most prominent findings is that registration in TB dispensaries is a risk factor for diagnostic delay. One of the likely reasons may be the gradual weakening capacity and transformation of TB dispensaries in recent years in China. Some local TB dispensaries have merged with the local CDC, so the diagnosis and treatment capacity of TB dispensaries has decreased significantly compared with the past. Secondly, with the improvement of living standards and their awareness of TB, patients with symptoms are more likely to choose to go to high level general hospital which were not the TB designated hospitals, and all the TB suspects should be transferred to TB dispensary or TB designated hospitals, the tortuous care seeking pathway might lead to diagnostic delay in some extent.

There are some important policy implications of this study for tuberculosis control in China. As we know, TB patients are still predominantly passive found in China, which relies heavily on the patient's medical 
treatment behavior, so a variety of approaches should be adopted to improve public awareness of TB, in such way to shorten the patient delay. The health system delay is affected by the ability of the doctors in the healthcare system and the institutional diagnostic skills, so it is important to improve the recognition of TB symptoms of all the health care workers in health facilities, especially in the eastern and rural areas. Besides this, to scale up of rapid diagnostic tests, enhance the diagnostic capacity of the health staffs, optimize the diagnostic algorithm and considering active case finding among some high risk groups.

\section{Limitations}

The risk factors of delayed diagnosis can be divided into three levels: socio-economic, clinical, and health system factors ${ }^{23}$. And the diagnosis delay has two parts, including patient delay (the time interval between the first symptom of tuberculosis and the first visit to the health care facilities) and health system delay (the time interval between the first visit to any health care facilities until the date of diagnosis). The health system delay is mainly due to health care facilities, it may due to lack of diagnosis facilities, availability of trained staff, lack of quality services and lack of effective supervision. In our study, the diagnosis time was the time interval between the first symptom of tuberculosis and the first confirmed diagnosis in health facilities. As a whole time, we can't get the detailed information of the two parts delay. The influencing factors of diagnosis time in this study are only limited to the general conditions and social-economic of the patients themselves, and the investigation of some clinical and health system factors needs to be supplemented. In view of the limitations of this study, it is necessary for NCTB to collect standardized data on patient visits as part of routine monitoring and evaluation. Ideally, this data should include both public and private sector patients and capture how many doctors have been seen before TB diagnosis, how long the process takes, and how much the patient costs.

\section{Conclusion}

In general, our study showed a significant delay in the diagnosis in China. The major factors associated with the diagnosis delay were related to regions, rural residence, asymptomatic and registration place. To improve the TB awareness among health care workers and public health, to promote the use of simple and rapid diagnostic test for TB at lowest level of the health care facilities are essential measures to shorten diagnosis delay.

\section{Declarations}

\section{Ethical Approval and Consent to participate}

The study was approved by the Ethics Committee of Chinese Center for Disease Control and Prevention (No.201625, dated 22 November 2016). The written informed consent process and the provision 15 US\$ to patients as reimbursement for costs related to travel for the interview were approved by the ethics committee. 


\section{Consent for publication}

Not applicable.

\section{Availability of data and materials}

The dataset and codebook used in this study are available on request from the corresponding author (zhanghui@chinacdc.cn, huizhang1974@126.com)

\section{Competing interests}

No potential conflict of interest was reported by the authors.

\section{Founding}

The author(s) received no specific funding for this work. This research was funded by the Economic Evaluation of Health Intervention for Prophylaxis of Latent Infections in Close Contactors of Tuberculosis Patients Project. The funders had no role in study design, data collection and analysis, decision to publish, or preparation of the manuscript. The project number is 41318148 .

\section{Author Contributions}

Conception and study design: $\mathrm{CX}, \mathrm{HZ}$

Development and piloting the data collection tools: $\mathrm{CX}, \mathrm{XMZ}, \mathrm{YL}, \mathrm{YYX}$

Data collection: $\mathrm{CX}, \mathrm{XMZ}, \mathrm{YL}, \mathrm{YYX}, \mathrm{HZ}$

Data entry: CX, XMZ, YL, YYX

Data analysis and interpretation: $\mathrm{CX}, \mathrm{XMZ}, \mathrm{HZ}$

Preparing the first draft: $\mathrm{CX}, \mathrm{XMZ}, \mathrm{HZ}$

\section{Acknowledgments}

We would like to thank all study participants, study nurses, and physicians.

\section{References}

1. Organization WH, Global tuberculosis report 2020, 2020

2. FG C, J M and FRG H, et al. Early detection of Tuberculosis. British Medical Journal 1942; 1: 535.

3. Wang L, Zhang H and Ruan Y, et al. Tuberculosis prevalence in China, 1990-2010; a longitudinal analysis of national survey data. Lancet 2014; 383: 2057-2064. Journal Article; Research Support, Non-U.S. Gov't. DOI: 10.1016/S0140-6736(13)62639-2. 
4. CDC C, China tuberculosis surveillance report 2019, Beijing, 2019

5. Meyssonnier $\mathrm{V}, \mathrm{Li} \mathrm{X}$ and Shen $\mathrm{X}$, et al. Factors associated with delayed tuberculosis diagnosis in China. Eur. J. Public Health 2013; 23: 253-257. DOI: 10.1093/eurpub/cks037.

6. Chen $\mathrm{H}$, Wang $\mathrm{T}$ and Liu $\mathrm{L}$, et al. Trend in risk of delay in diagnosis of new pulmonary tuberculosis in Northwest China from 2008 to 2017. Bmc Infect. Dis. 2019; 19. DOI: 10.1186/s12879-019-3725-9.

7. Zhou C, Tobe RG and Chu J, et al. Detection delay of pulmonary tuberculosis patients among migrants in China: a cross-sectional study. The International Journal of Tuberculosis and Lung Disease 2012; 16: 1630-1636. DOI: 10.5588/ijtld.12.0227.

8. Xu X, Liu J and Cao S, et al. Delays in care seeking, diagnosis and treatment among pulmonary tuberculosis patients in Shenzhen, China. The International Journal of Tuberculosis and Lung Disease 2013; 17: 615-620. DOI: 10.5588/ijtld.12.0231.

9. Li X, Jiang $S$ and $L i X$, et al. Predictors on delay of initial health-seeking in new pulmonary tuberculosis cases among migrants population in East China. Plos One 2012; 7: e31995. DOI: 10.1371/journal.pone.0031995.

10. Lin $X$, Chongsuvivatwong $V$ and Geater $A$, et al. The effect of geographical distance on TB patient delays in a mountainous province of China. The international journal of tuberculosis and lung disease 2008; 12: 288.

11. Data N, National Bureau of Statistics, 2020

12. MK G. The role of the public and private sectors in China's health care system. Glob Soc Welf 2016; 3 : 193-200.

13. CDC C, Baseline survey report of Gates foundation TB project (Phase II), Beijing, 2018

14. Yamasaki-Nakagawa M, Ozasa $\mathrm{K}$ and Yamada N, et al. Gender difference in delays to diagnosis and health care seeking behaviour in a rural area of Nepal. The international journal of tuberculosis and lung disease 2001; 5: 24.

15. Sreeramareddy CT, Qin ZZ and Satyanarayana S, et al. Delays in diagnosis and treatment of pulmonary tuberculosis in India: a systematic review. The International Journal of Tuberculosis and Lung Disease 2014; 18: 255-266. DOI: 10.5588/ijtld.13.0585.

16. Karim F, Islam MA and Chowdhury A, et al. Gender differences in delays in diagnosis and treatment of tuberculosis. Health Policy Plann. 2007; 22: 329-334. DOI: 10.1093/heapol/czm026.

17. Wandwalo ER and Morkve O. Delay in tuberculosis case-finding and treatment in Mwanza, Tanzania. Int J Tuberc Lung Dis 2000; 4: 133-138. Comparative Study; Journal Article; Research Support, NonU.S. Gov't.

18. Zhi-hong $\mathrm{Y}$, Ping $\mathrm{C}$ and Cong $\mathrm{C}$. Research on detective delay and influence factors in youth patients with pulmonary tuberculosis. Clinical Focus 2011; 26: 1029-1032.

19. Yan-ming $Y$, Xue-wen $P$ and Yan-yong F. Investigation of an outbreak of tuberculosis in an adult education centre in Tianjin. Jouran/ Tuberculosis Lung Health 2019; 8: 65-68. 
20. Jue L, Li-tian $Y$ and Xiao-na L. Investigation and analysis of a tuberculosis cluster epidemic in a college in Shanxi. Journal of Shanxi Medical University 2020; 51: 689-695.

21. Li-xia W, Shi-ming $C$ and Ming-ting C, et al. The fifth national tuberculosis epidemiological survey in 2010. Chinese Journal of Antituberculosis 2012; 34: 485-508.

22. Segagni $L L$, Quaglio $G$ and Atzori A, et al. Factors associated with patient and health care system delay in diagnosis for tuberculosis in the province of Luanda, Angola. Bmc Infect. Dis. 2013; 13: 168. Journal Article; Research Support, Non-U.S. Gov't. DOI: 10.1186/1471-2334-13-168.

23. WHO, The global plan to stop TB 2011-2015: transforming the fight towards elimination of tuberculosis, 2010. 10.1371/journal.pone.0108591

\section{Figures}

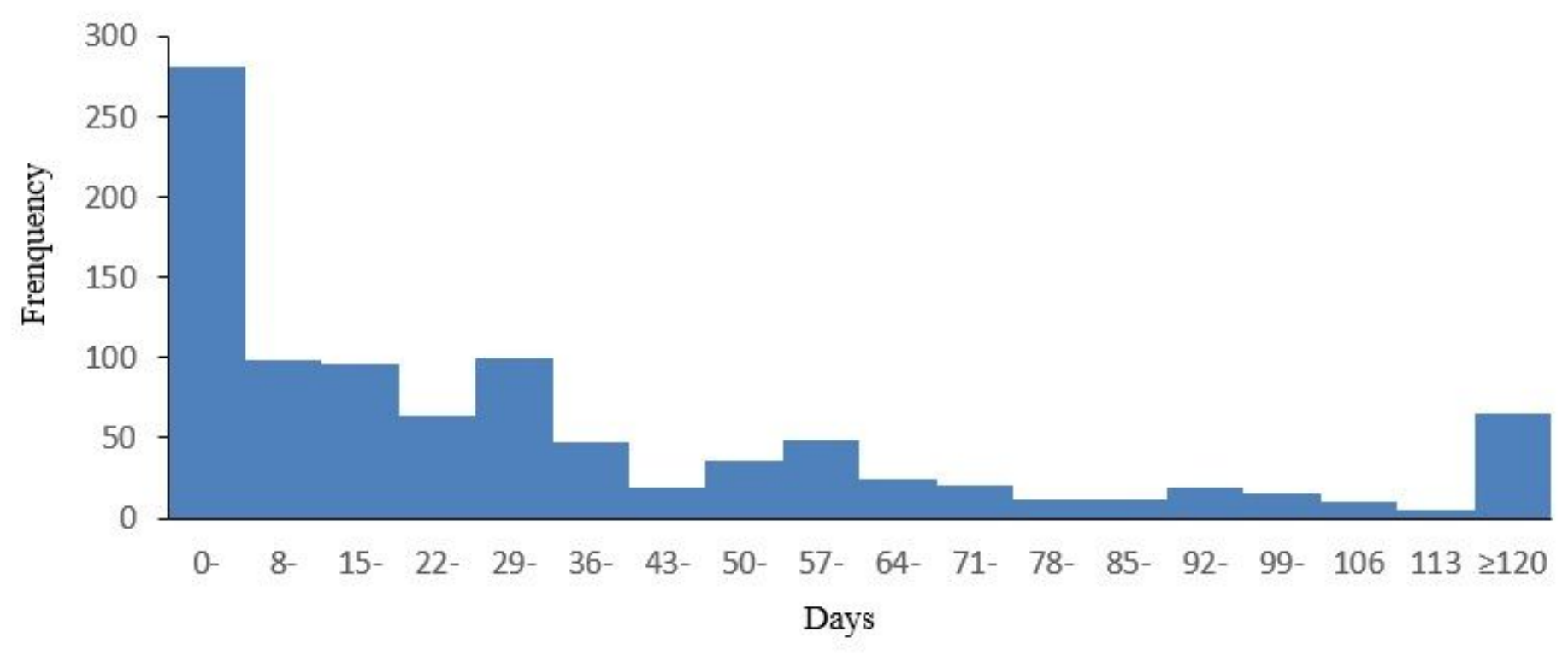

Figure 1

Diagnosis time in days. The figure shows the time from the onset of symptoms to the diagnosis, among 974 pulmonary TB patients under NTP, during Jan to June 2017, in China

\section{Supplementary Files}

This is a list of supplementary files associated with this preprint. Click to download.

- 7Annexl.Multistagestratifiedclustersampling.docx

- 8AnnexIISampleNumber.docx 